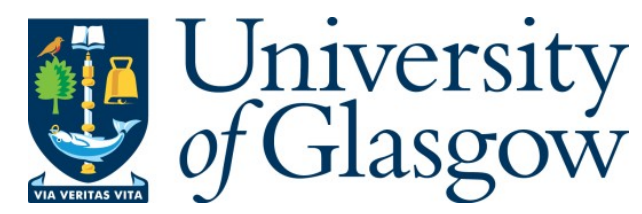

Le, T.M .H., Gallipoli, D., Sanchez, M ., and Wheeler, S. (2013) Rainfallinduced differential settlements of foundations on heterogeneous unsaturated soils. Geotechnique, 63 (15). pp. 1346-1355. ISSN 0016-8505

Copyright $\odot 2013$ ICE Publications

A copy can be downloaded for personal non-commercial research or study, without prior permission or charge

Content must not be changed in any way or reproduced in any format or medium without the formal permission of the copyright holder(s)

When referring to this work, full bibliographic details must be given

http://eprints.gla.ac.uk/85221/

Deposited on: 31 M arch 2014

Enlighten - Research publications by members of the U niversity of Glasgow http://eprints.gla.ac.uk 


\title{
Rainfall-induced differential settlements of foundations on heterogeneous unsaturated soils
}

\author{
T. M. H. LE* ${ }^{*}$ D. GALLIPOLI†, M. SANCHEZ $\ddagger$ and S. WHEELER
}

\begin{abstract}
This study stochastically investigates the rainfall-induced differential settlement of a centrally loaded, rigid strip foundation on an unsaturated soil with spatially varying values of either preconsolidation stress or porosity. The differential settlement (between the two foundation ends) is calculated at various times during rainfall by way of a coupled, hydro-mechanical, finite-element analysis. The Barcelona basic model describes the mechanical behaviour of the soil, and the van Genuchten relationships describe water retention and permeability. The variability of soil properties is modelled by means of random fields with spatial correlation in the framework of a Monte Carlo simulation. The study demonstrates that the occurrence of rainfall-induced differential settlements can be consistently analysed using concepts of unsaturated soil mechanics and random field theory. Results show that differential settlements can be vastly underpredicted (or even completely missed) if random heterogeneity and partial saturation are not simultaneously considered. The variation of differential settlements and their statistics during the rainfall depend on the magnitude of the applied load and the statistics of soil variability. Moreover, the transient phase of infiltration and a spatial correlation length equal to the width of the foundation pose the highest risk of differential settlement.
\end{abstract}

KEYWORDS: finite-element modelling; footings/foundations; partial saturation; settlement; statistical analysis; suction

\section{INTRODUCTION}

Excessive foundation settlements can have serious consequences on the safety, aesthetics and cost of structures, especially when they occur non-uniformly, which often leads to tilting or cracking of buildings. Spatial variability of soil properties is a prime cause of non-uniform foundation settlements. The settlement of shallow foundations on heterogeneous soils has been investigated probabilistically in numerous studies. Earlier works (e.g. Wu \& Kraft, 1967; Resendiz \& Herrera, 1969) demonstrated the feasibility of probabilistic foundation analysis, but did not take into account spatial correlation of soil properties. This limitation was later overcome by Baecher \& Ingra (1981), Zeitoun \& Baker (1992), Paice et al. (1994, 1996), Fenton \& Griffiths (2002), Fenton et al. (2005) and Popescu et al. (2005). Griffiths \& Fenton (2009) highlighted that foundation settlements are dominated by soil regions with low stiffness, and that ignoring spatial correlation can lead to unconservative predictions.

All the above studies deal with saturated soils, and little research has so far been undertaken concerning foundations on unsaturated soils. Among this rare research, Kawai et al. (2007) used the constitutive model by Karube \& Kawai (2001) to study the non-uniform settlements induced by rainfall infiltration into a compacted earth fill of variable thickness. The authors highlighted the role played by simul-

Manuscript received 25 November 2012; revised manuscript accepted 13 June 2013.

Discussion on this paper is welcomed by the editor.

* Department of Civil and Transport Engineering, Norwegian University of Science and Technology (NTNU), Trondheim, Norway. $\dagger$ Laboratoire SIAME, Université de Pau et des Pays de l'Adour, Anglet, France.

$\$$ Zachry Department of Civil Engineering, Texas A\&M University, College Station, USA.

$\S$ Infrastructure \& Environment Research Division, School of Engineering, University of Glasgow, UK. taneous occurrences of elastic swelling and plastic compression during wetting (for shallow and deep soil elements respectively) in causing non-uniform settlements.

The relative lack of research in this area is due mainly to the complex non-linear behaviour of unsaturated soils, which is caused by the coexistence of air and water within pores. Various constitutive models for unsaturated soils have been developed (e.g. Fredlund et al., 1978; Alonso et al., 1990; Josa et al., 1992; Bolzon et al., 1996; Wheeler et al., 2003; Gallipoli et al., 2003). Among these models, the Barcelona basic model (BBM) proposed by Alonso et al. (1990) is arguably the best known, and has provided the fundamental theoretical framework on which several later models were built. Through the introduction of the loading-collapse (LC) yield curve, the BBM has described, for the first time, important features of the behaviour of unsaturated soils, such as the increase of preconsolidation stress with increasing suction, and the occurrence of wetting-induced (elastic) swelling or (plastic) compression (i.e. 'collapse'), depending on stress levels. These features are particularly relevant to the analysis of foundation settlements caused by water infiltration.

During infiltration, the soil suction reduces, and this can induce non-uniform settlements of the overlying foundation, owing to the spatial heterogeneity of either preconsolidation stress or porosity. Preconsolidation stress controls the amount of swelling and/or collapse-compression during suction reduction (i.e. wetting) in unsaturated soils. Both swelling and collapse-compression play an important role in the differential settlement of unsaturated foundations, and so the variability of preconsolidation stress is expected to have a significant effect on differential settlements during rainfall infiltration. On the other hand, porosity directly influences soil permeability, which controls the evolution of pore water pressures during rainfall infiltration. The variation of pore water pressure (and hence of suction) determines the occurrence of swelling and/or collapse-compression (as discussed later), and hence governs foundation settlements in unsaturated soils. 
Therefore the variability of porosity has considerable influence on foundation performance during rainfall infiltration.

The present study combines unsaturated soil mechanics with stochastic modelling to investigate the effect of the spatial variability of either preconsolidation stress or porosity on the settlement of a shallow rigid foundation on an unsaturated soil subjected to rainfall infiltration. Only one of the two parameters investigated (i.e. preconsolidation stress or porosity) is stochastically varied at a time while all other model parameters are kept constant, in order to single out the effect of the varying parameter. The simultaneous variation of both these parameters is outside the scope of the current paper, although it would be of interest for future investigations. The study considers the influence of the foundation load and of the statistical parameters (mean, standard deviation and correlation length) of preconsolidation stress and porosity. This will help to highlight the factors that increase the risk of excessive differential settlement between foundation ends.

\section{THE MODEL}

A centrally loaded, rough strip foundation $(8 \mathrm{~m} \times 1 \mathrm{~m})$ is modelled as a two-dimensional, plane-strain problem (Fig. 1) using the finite-element (FE) code Code_Bright (Olivella et al., 1996). Soil is assumed to behave according to the BBM, while the foundation itself is linear elastic with an extremely high Young's modulus $\left(10^{9} \mathrm{MPa}\right)$, and hence acts as a rigid body compared with the underlying soil. Differential settlements (due to a rigid rotation of the foundation) are measured as the difference in vertical displacement between the foundation extremities (i.e. points $\mathrm{B}$ and $\mathrm{C}$ in Fig. 1).

The stress distribution in the soil domain prior to infiltration is established in three loading steps.

(a) Application of gravity from a virtually weightless state (i.e. $\sim 0.001 \mathrm{MPa}$ in all directions) by increasing gravitational acceleration from zero to $9 \cdot 81 \mathrm{~m} / \mathrm{s}^{2}$.

(b) Application of foundation weight by gradually increasing the unit weight of the foundation material (from zero to $\sim 27 \mathrm{kN} / \mathrm{m}^{3}$ ).

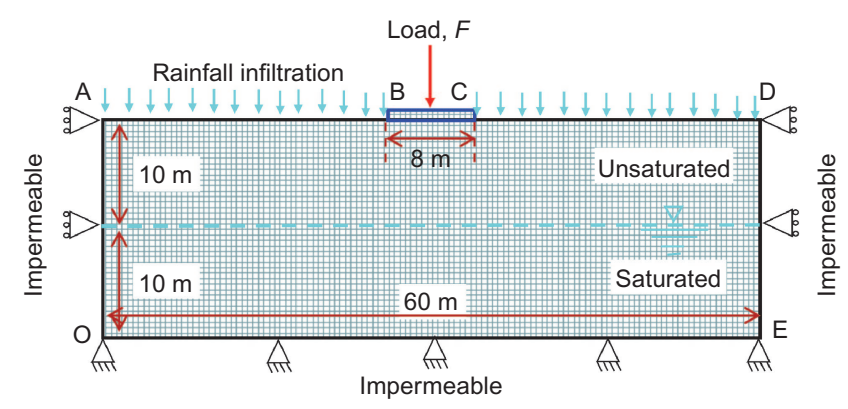

Fig. 1. Foundation model (c) Application of point load $(F)$ at the centre of the foundation.

The strains caused by gravity are disregarded, given that step (a) is a mere numerical procedure to obtain a physically reasonable initial stress state in the soil. The deformations caused by foundation weight and point load are instead retained, as they are effects of construction. The parameter values of the BBM (Table 1) are adapted from Alonso et al. (1990), and refer to compacted kaolin (derived from experimental data of Karube, 1988). In Table $1, \kappa$ and $\kappa_{\mathrm{s}}$ are the elastic compressibility indexes associated with changes of mean net stress $p$ (at constant suction $s$ ) and changes of suction $s$ (at constant $p$ ) respectively. Parameter $\lambda(0)$ is the slope of the normal compression line (NCL) at zero suction (i.e. at saturation), $r$ defines the limit value of the NCL slope at infinite suction, and $\beta$ fixes the rate at which the NCL slope changes with suction. Parameter $p^{\mathrm{c}}$ corresponds to the value of the hardening parameter $p_{0}^{*}$ (i.e. the saturated preconsolidation stress) at which yielding does not depend on suction. Parameter $M$ is the slope of the critical state line at constant suction in the shear stress-mean net stress $(q-p)$ plane, $\alpha$ defines the degree of non-associativity of the flow rule, and $e_{0}$ is the initial void ratio.

The initial pore water pressure is hydrostatic, and in equilibrium with the initial water table (Fig. 1). Pore water pressures are maintained constant at every node during steps (b) and (c) to simulate 'drained' conditions. After the applications of the foundation weight and point load, a constant rainfall infiltration rate is imposed at the surface, except underneath the foundation (i.e. over $\mathrm{AB}$ and $\mathrm{CD}$ but not over BC in Fig. 1). The 'seepage boundary condition' is employed to simulate rainfall infiltration: that is, a constant infiltration rate is imposed on boundaries $\mathrm{AB}$ and $\mathrm{CD}$ until ponding occurs and a zero pore water pressure is attained at the surface. Thereafter the boundary condition changes from the imposition of a constant infiltration rate to the imposition of a constant pore water pressure equal to zero (UPC, 2009; Le et al., 2012). A rainfall intensity of $43.2 \mathrm{~mm} /$ day (a realistic value for the UK climate) is assumed (Met Office, 2011) over a relatively long period (15 days) to investigate transient states. Given that boundaries DE, OE and OA are impermeable, gradual accumulation of water takes place inside the soil domain, leading to the water table rise during the rainfall. Differential settlements are recorded every day over the rainfall period.

The water retention (equation (1)) and permeability (equation (4)) functions by van Genuchten are employed to link the effective degree of saturation $S_{\mathrm{e}}$ to suction, and the relative permeability $k_{\mathrm{r}}$ to $S_{\mathrm{e}}$ respectively (van Genuchten, 1980, van Genuchten \& Nielsen, 1985); in equation (1) the maximum and residual values of degree of saturation $\left(S_{\mathrm{s}}\right.$ and $S_{\mathrm{r}}$ ) are equal to 1 and $0 \cdot 01$ respectively. Parameters $S_{\mathrm{e}}$ (related to the air entry suction) and $k_{\mathrm{s}}$ (saturated permeability) are linked to soil porosity $\phi$ through parameters $\eta, \phi_{0}$, $s_{\mathrm{e} 0}$ and $k_{\mathrm{s} 0}$ according to equations (2) and (3) respectively

Table 1. Soil parameters

\begin{tabular}{l|c|c|c|c|c}
\hline Mechanical & \multicolumn{2}{c}{ Hydraulic } \\
\hline Parameter & Value & Parameter & Value & Parameter & Value \\
\hline$\kappa$ & $0 \cdot 011$ & $\lambda(0)$ & $0 \cdot 065$ & $k_{\mathrm{s} 0:} \mathrm{m} / \mathrm{s}$ & $10^{-5}$ \\
$\kappa_{\mathrm{s}}$ & $0 \cdot 005$ & $r$ & $0 \cdot 75$ & $m$ & $0 \cdot 2$ \\
$k$ & $0 \cdot 8$ & $\beta: \mathrm{MPa}^{-1}$ & 20 & $s_{\mathrm{e} 0:} \mathrm{MPa}$ & $0 \cdot 02$ \\
$\alpha$ & $0 \cdot 3$ & $p^{\mathrm{c}}: \mathrm{MPa}$ & $0 \cdot 01$ & $\phi_{0}$ & $0 \cdot 3$ \\
$e_{0}$ & $0 \cdot 5$ & $M$ & 1 & $\eta$ & 5 \\
\hline
\end{tabular}


(Kozeny, 1927; Rodriguez, 2006; Zandarín et al., 2009). Model parameter $m$ controls the shape of the water retention curve and the permeability function. Parameter $\eta$ controls the rate at which $s_{\mathrm{e}}$ changes from its reference value $s_{\mathrm{e} 0}$ when $\phi$ deviates from its reference value $\phi_{0}$. Finally, unsaturated flow $\boldsymbol{q}$ is calculated using the generalised Darcy's law (equation (5)). These constitutive relationships have been discussed in detail by Le et al. (2012) and Le (2012).

$$
\begin{aligned}
& S_{\mathrm{e}}=\frac{S-S_{\mathrm{r}}}{S_{\mathrm{s}}-S_{\mathrm{r}}}=\left[1+\left(\frac{s}{s_{e}}\right)^{1 /(1-m)}\right]^{-m} \\
& s_{\mathrm{e}}=s_{\mathrm{e} 0} \exp \left[\eta\left(\phi_{0}-\phi\right)\right] \\
& k_{\mathrm{s}}=k_{\mathrm{s} 0} \frac{\phi^{3}}{(1-\phi)^{2}} \frac{\left(1-\phi_{0}\right)^{2}}{\phi_{0}^{3}} \\
& k_{\mathrm{r}}=\sqrt{S_{\mathrm{e}}}\left[1-\left(1-S_{\mathrm{e}}^{1 / m}\right)^{m}\right]^{2} \\
& \boldsymbol{q}=-k_{\mathrm{s}} k_{\mathrm{r}} \nabla\left(\frac{u_{\mathrm{w}}}{\rho_{\mathrm{w}} \boldsymbol{g}}+z\right)
\end{aligned}
$$

The symbols $u_{\mathrm{w}}, \rho_{\mathrm{w}}, \boldsymbol{g}$ and $z$ indicate the pore water pressure, water density, gravitational acceleration and elevation coordinate respectively. The values of the hydraulic parameters (Table 1) are selected to maintain numerical stability and avoid extreme responses (e.g. excessively permeable or impermeable soil).

\section{SPATIAL VARIABILITY OF SOIL PROPERTIES \\ Preconsolidation stress}

In the BBM, the hardening parameter coincides with the saturated isotropic preconsolidation stress $p_{0}^{*}$, the value of which defines the yield surface in the stress space. The value of $p_{0}^{*}$ is dictated by the highest stress level previously experienced by the soil, and hence increases with depth owing to growing overburden weight (e.g. Bartlett \& Alcorn, 2004). The depth-dependent value of $p_{0}^{*}$ is reproduced in the present study by first establishing an underlying profile of $p_{0}^{*}$ that corresponds to a normally consolidated soil whose stress state is obtained by the application of gravity (gravity is increased to $9.81 \mathrm{~m} / \mathrm{s}^{2}$, starting from a soil with virtually zero stress and a small initial value of $p_{0}^{*}=0.04 \mathrm{MPa}$ ). During gravity application, if yielding occurs at a given element, the corresponding value of $p_{0}^{*}$ increases to a level that is greater for larger vertical stresses (i.e. for greater depths). In this way, one obtains a realistic, depth-dependent profile of $p_{0}^{*}$, which is used as the underlying profile for the subsequent generation of the random $p_{0}^{*}$. Besides the overburden weight, the value of $p_{0}^{*}$ might also be modified by other factors, such as weathering and bonding, and hence can be non-uniform, even at the same depth. This is taken into account in the current study by utilising a two-dimensional, isotropic, random field of positive increments $\Delta p_{0}^{*}$ by way of the local average subdivision method for each realisation (Fenton, 1990). Note that the correlation length of a soil property is usually larger in the horizontal than in the vertical direction, but this anisotropic effect is not taken into account in the current study. The values of $\Delta p_{0}^{*}$ are mapped onto the elements of the FE mesh and added to the underlying gravity-induced values of $p_{0}^{*}$ to create a randomly heterogeneous variation of $p_{0}^{*}$. A $\log$-normal distribution is assumed for $\Delta p_{0}^{*}$ to ensure that the final random value of $p_{0}^{*}$ is never smaller than the underlying value of $p_{0}^{*}$ (as this would be numerically inadmissible and unrealistic). In this study, the values of the mean $\mu\left(\Delta p_{0}^{*}\right)$, coefficient of variation $\mathrm{COV}_{\Delta p_{0}^{*}}$ and correlation length $\theta\left(\Delta p_{0}^{*}\right)$ are $0.04 \mathrm{MPa}$, 0.4 and $8 \mathrm{~m}$ respectively, unless otherwise specified.

This study employs an FE mesh of 4800 identical four- noded square elements, each with four integration points and an area of $0.5 \mathrm{~m} \times 0.5 \mathrm{~m}$ (Fig. 1). In a generic realisation, a $60 \mathrm{~m} \times 20 \mathrm{~m}$ random field of approximately 5500 identical square cells $(\approx 0.47 \mathrm{~m} \times 0.47 \mathrm{~m})$ is superimposed on the mesh. Each FE element is then assigned the random value of $\Delta p_{0}^{*}$ of the cell having the closest centroid to the centroid of that element. The mapping algorithm has been described in detail in Le (2012) and Le et al. (2012).

A different random field of $\Delta p_{0}^{*}$ is employed in each FE realisation before application of the foundation weight and point load (i.e. between steps (a) and (b) above). Fig. 2 shows the random variation of $p_{0}^{*}$ along a generic vertical profile of a sample realisation, together with the underlying gravity-induced profile.

After adding $\Delta p_{0}^{*}$, the soil domain becomes overconsolidated, with a random spatially varying degree of overconsolidation (Fig. 3(a)). Depending on the degree of overconsolidation, the subsequent applications of the foundation weight and the load (i.e. steps (b) and (c) above) cause elastic and, possibly, plastic deformations in each element.

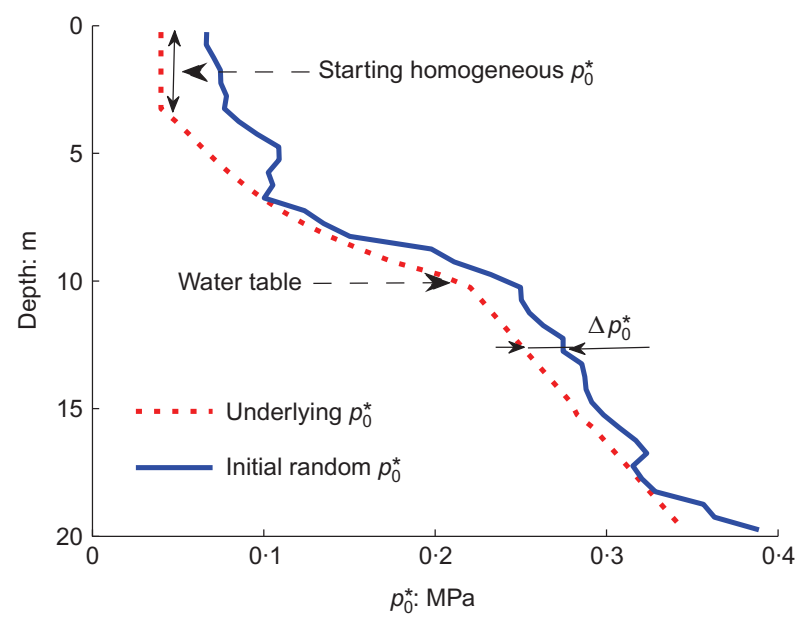

Fig. 2. Sample random $p_{0}^{*}$ profile after adding $\Delta p_{0}^{*}$ increment to underlying gravity-induced profile $\left(\mu\left(\Delta p_{0}^{*}\right)=0 \cdot 04 \mathrm{MPa}, \mathrm{COV}_{\Delta p_{0}^{*}}=\right.$ $\left.0 \cdot 4, \theta\left(\Delta p_{0}^{*}\right)=8 \mathrm{~m}\right)$

Saturated initial isotropic yield stress, $p_{0}^{*}: \mathrm{MPa}$ 0.040 .080 .120 .160 .200 .240 .280 .320 .360 .40

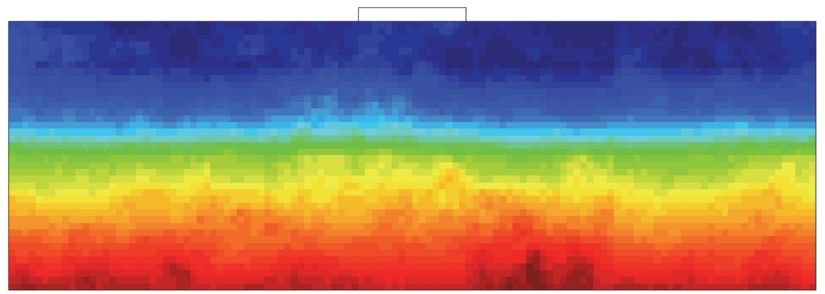

(a)

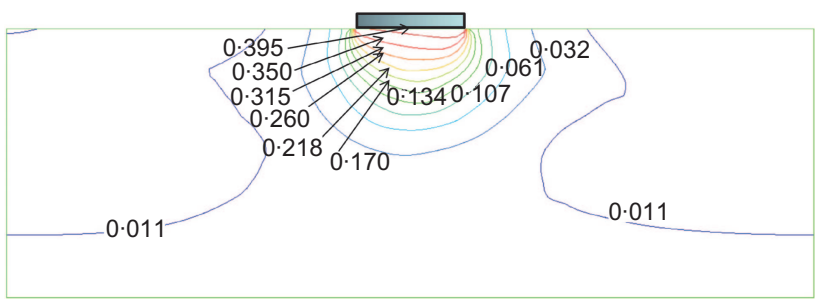

(b)

Fig. 3. Sample realisation: (a) random $p_{0}^{*}$ field (before application of foundation weight and point load); (b) corresponding displacement contours $(\mathrm{m})$ after 15 days of rainfall $\left(\mu\left(\Delta p_{0}^{*}\right)=0 \cdot 02 \mathrm{MPa}\right.$, $\left.\operatorname{COV}_{\Delta p_{0}^{*}}=0.4 \mathrm{MPa}, \theta\left(\Delta p_{0}^{*}\right)=8 \mathrm{~m}\right)$ 
The subsequent drop in suction, due to water infiltration, produces elastic swelling and/or plastic collapse with reduction of strength. The particular response of a given soil element depends on its evolving stress state relative to the initial yield locus. The combination of responses from all elements determines the settlement of the foundation. A differential settlement $\delta_{\mathrm{s}}$ occurs because the heterogeneity of $p_{0}^{*}$ produces uneven cumulative strains at the two foundation ends (Fig. 3(b)).

For a given realisation, the value of $\delta_{\mathrm{s}}$ is calculated by subtracting the vertical displacement at $\mathrm{C}$ from that at $\mathrm{B}$ (Fig. 1), and hence it can be negative or positive. Because of symmetry, positive and negative values of $\delta_{\mathrm{s}}$ are expected to occur with similar frequencies, and provided the number of realisations is sufficiently large, the resulting probability distribution function (pdf) of $\delta_{\mathrm{s}}$ should be symmetrical about zero. Indeed, frequency histograms of $\delta_{\mathrm{s}}$, computed at different times during the rainfall, strongly suggest a symmetrical distribution that is well interpolated by the normal distribution (Fig. 4). The adequacy of this interpolation was confirmed by probability plots and $\chi^{2}$ goodness-of-fit tests.

\section{Porosity}

Heterogeneity of porosity leads to spatial variability of water retention (equation (2)) and permeability (equation (3)) properties, which affects flow characteristics (Le, 2012; Le et al., 2012). In this study, a random variation of porosity is introduced over the soil domain prior to gravity application (the initial stress state therefore takes into account the spatial non-uniformity of soil weight due to porosity variation). For each realisation, a random field of void ratio $e$ is first generated, which is then converted into a porosity field $(\phi=e /(1+e))$. The choice of generating random values of $e$ instead of $\phi$ simplifies the analysis. This is because the former variable spans the whole positive range, and can thus be appropriately modelled by a log-normal pdf. This distribution theoretically covers the whole positive range, and requires only two parameters (i.e. the mean and standard deviation). On the other hand, the values of $\phi$ are bounded between 0 and 1 , and are most appropriately modelled by a bounded distribution (e.g. the bounded-tanh distribution). Bounded distributions are more complicated to define, as they require a larger number of parameters (e.g. the mean, standard deviation, bound values and location factor).

The values of $\mu(e), \mathrm{COV}_{e}$ and $\theta(e)$ are $0.5,0.8$ and $8 \mathrm{~m}$, unless otherwise specified, and the point load $F$ is kept constant at $1 \mathrm{MN} / \mathrm{m}$. The mapping of random porosity onto the FE mesh follows a procedure similar to the case of the random variation of preconsolidation stress.

The initial distribution of $p_{0}^{*}$ coincides with the gravityinduced depth-dependent profile, as explained in the pre-

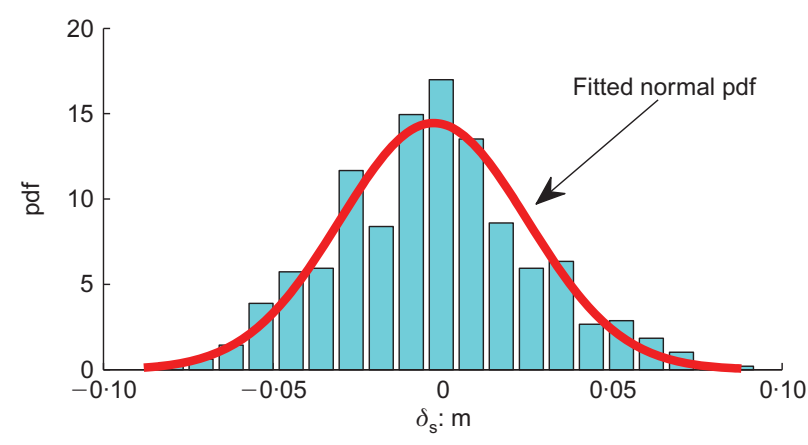

Fig. 4. Frequency histogram and fitted normal probability distribution function for $\delta_{\mathrm{s}}$ with random $p_{0}^{*}(F=1 \mathrm{MN} / \mathrm{m}$, $\left.\mu\left(\Delta p_{0}^{*}\right)=0.02 \mathrm{MPa}, \mathrm{COV}_{\Delta p_{0}^{*}}=0 \cdot 4, \theta\left(\Delta p_{0}^{*}\right)=8 \mathrm{~m}\right)$ vious section. Therefore the vast majority of soil elements are normally consolidated, with the exception of a few overconsolidated elements in the top soil layer (where gravity-induced stress levels are smaller than the yield threshold imposed by the starting value of $p_{0}^{*}=0.04 \mathrm{MPa}$ ).

The spatial variation of porosity causes a non-symmetrical distribution of hydraulic properties, and hence a non-symmetrical evolution of pore water pressures during rainfall. Moreover, normally consolidated soil elements experience plastic collapse during wetting, which may induce further significant changes of porosity. This leads to a non-symmetrical plastic deformation of the soil, and hence to differential settlements (Fig. 5). Similar to the case of the random variation of preconsolidation stress, the histograms of differential settlement, at different rainfall times, are well interpolated by the normal distribution (Fig. 6).

\section{HETEROGENEITY OF PRECONSOLIDATION STRESS Influence of foundation load}

The magnitude of $F$ defines the soil stress state prior to rainfall. For each realisation of random $p_{0}^{*}$, six analyses were performed with different values of $F(0 \cdot 25,0 \cdot 5,1,2,4$ and $8 \mathrm{MN} / \mathrm{m})$.

To facilitate understanding of the effect of foundation load, Fig. 7 shows three schematic stress paths that approximately mimic soil behaviour during application of the loads of different magnitudes and subsequent wetting. For simplicity, the shear stress is assumed to be zero (i.e. stress state is isotropic) in all stress paths; in reality, however, shear stress is non-zero, and the value of $\delta_{\mathrm{s}}$ is governed by both volumetric and shear strains. A non-associated flow rule with a value of $\alpha$ considerably less than $1(\alpha=0 \cdot 3)$ is adopted: hence the error caused by this assumption is likely to be insignificant.

In stress path OAB (Fig. 7(a)), the application of a small value of $F\left(\mathrm{O}\right.$ to $\mathrm{A}$ ) induces a stress state $p<p_{0}^{*}<p_{0}$, and hence an elastic decrease of $v$. This is followed by rainfall infiltration and consequent suction reduction (A to B), thus producing an elastic increase of specific volume $v$ (Fig. 7(b)) In stress path OCDE (Fig. 7(a)), the application of a moderate value of $F$ (O to $\mathrm{C}$ ) induces a stress state $p_{0}^{*}<p<p_{0}$, and hence an elastic decrease of $v$. During subsequent infiltration, the value of $v$ increases elastically until the yield locus is reached (C to $\mathrm{D})$, but then decreases plastically as suction reduces further (D to E) (Fig. 7(b)). In stress path OFGH (Fig. 7(a)), the application of a large value of $F$ induces a stress state $p_{0}^{*}<p_{0}<p$ and an elastic decrease of $v$ until yielding (O to F), followed by a plastic decrease (F to G) (Fig. 7(b)). The subsequent reduction of suction induces plastic compression, leading to a further decrease in $v(\mathrm{G}$ to $\mathrm{H})$.

Although the value of $\delta_{\mathrm{s}}$ can be negative or positive, the results are presented subsequently in terms of absolute value $\left|\delta_{\mathrm{s}}\right|$, because in practice it is the magnitude of the differential settlement that is of particular concern, irrespective of its sign.

Large values of $F$ can lead to the possible occurrence of all the above three stress paths, with shallow soil elements being subjected to larger increases in $p$ (prevalence of scenario OFGH) and deep soil elements experiencing only a small rise in $p$ (prevalence of scenario $\mathrm{OAB}$ ). This leads to large possible differences in the change of $v$ (e.g. difference between $\mathrm{B}$ and $\mathrm{H}$ in Fig. 7(b)) between symmetrical soil regions. Conversely, for small and intermediate values of $F$, the increase in $p$ is not large enough to induce stress path $\mathrm{OFGH}$, and most soil elements follow either path OCDE or path OAB (Fig. 7(a)). This produces smaller differences of $v$ (e.g. difference between B and E in Fig. 7(b)) between symmetrical soil regions than in the previous case. The values 


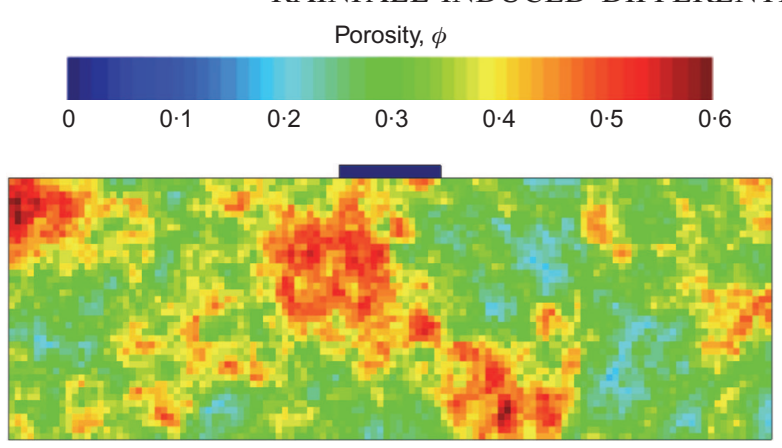

(a)

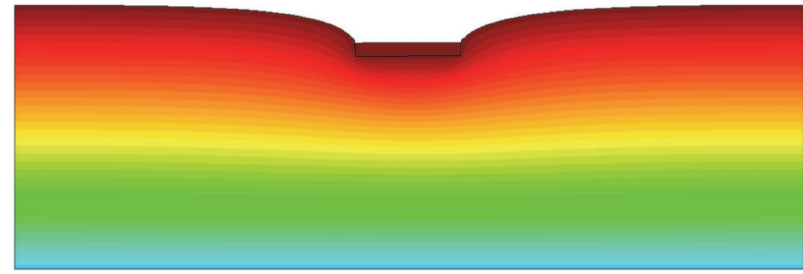

(c)

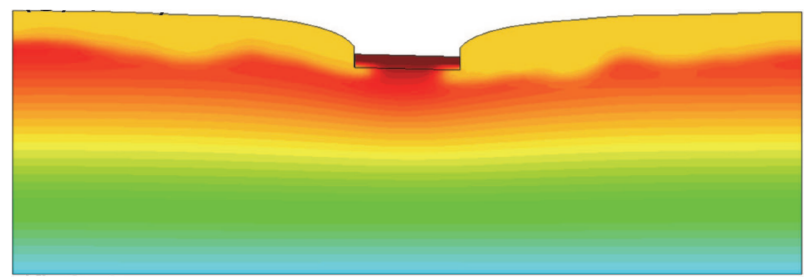

(e)

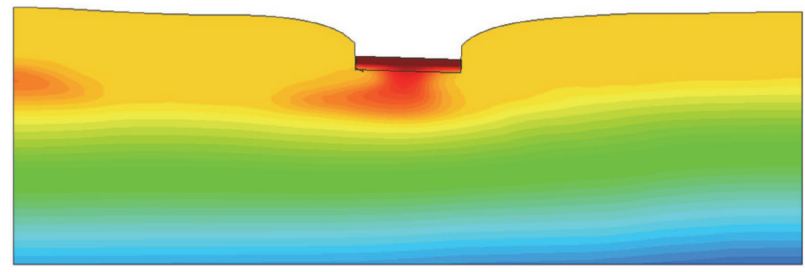

(g)

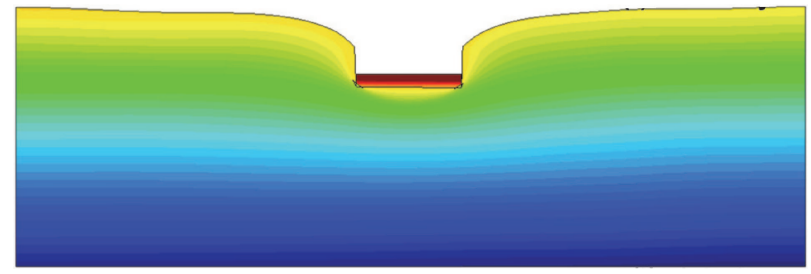

(i)
Pore water pressure: $\mathrm{MPa}$

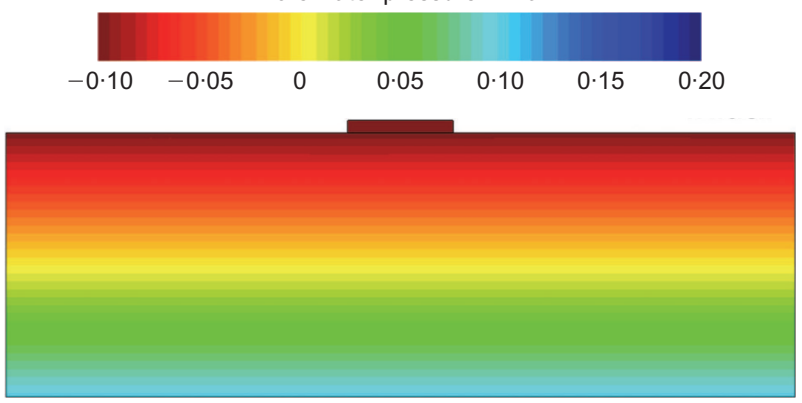

(b)

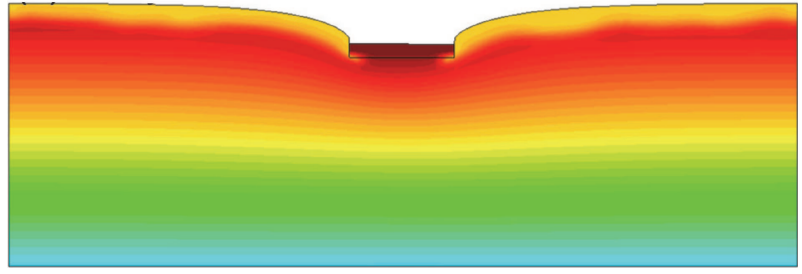

(d)

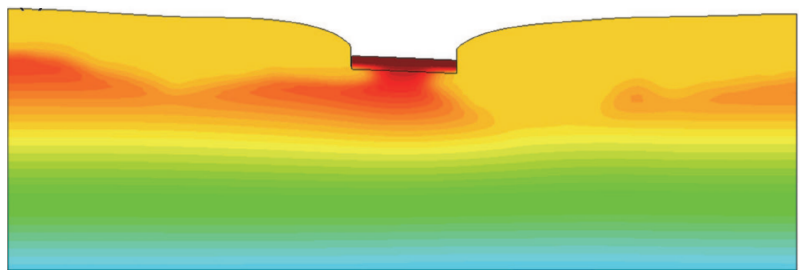

(f)

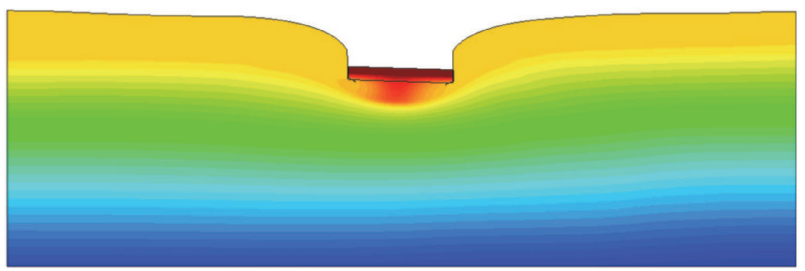

(h)

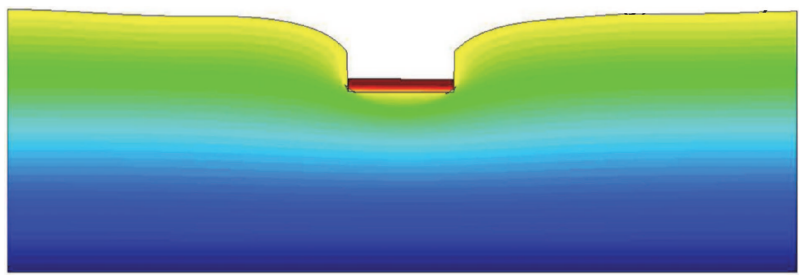

(j)

Fig. 5. Sample realisation: (a) random porosity field. Corresponding pore water pressures and foundation settlements (scale factor $=10$ ) at different times during rainfall: (b) initial; (c) day 0 ; (d) day 2; (e) day 4; (f) day 6; (g) day 8; (h) day 10; (i) day 12; (j) day 14 ( $\mu(e)=0.5$, $\left.\operatorname{COV}_{e}=0 \cdot 4, \theta(e)=8 \mathrm{~m}\right)$

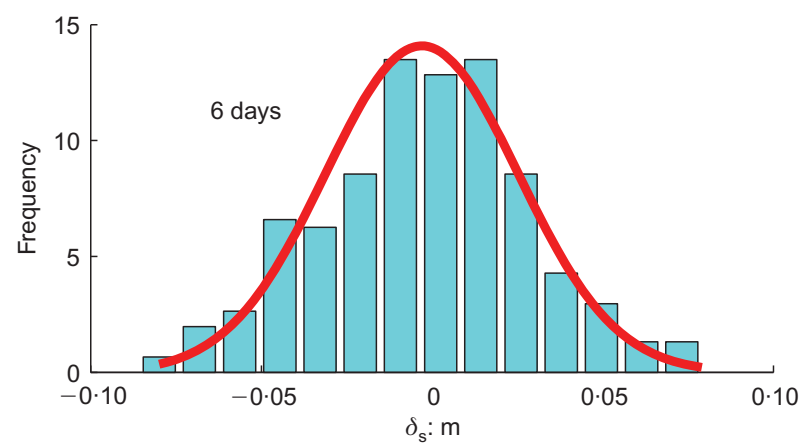

Fig. 6. Frequency histogram and fitted normal probability distribution for $\delta_{\mathrm{s}}$ of foundation on soil with random porosity $\left(F=1 \mathrm{MN} / \mathrm{m}, \mu(e)=0.5 \mathrm{COV}_{\mathrm{e}}=0 \cdot 4, \theta(e)=8 \mathrm{~m}\right)$ of $\mu\left(\left|\delta_{\mathrm{s}}\right|\right)$ and $\sigma\left(\left|\delta_{\mathrm{s}}\right|\right)$ therefore tend to increase with increasing values of $F$ (Fig. 8). It is important, though, to appreciate that the trends observed here are relevant to the assumed statistical parameters $\mu\left(\Delta p_{0}^{*}\right)=0.02 \mathrm{MPa}, \mathrm{COV}_{\Delta p_{0}^{*}}=0.4$ and $\theta\left(\Delta p_{0}^{*}\right)=8 \mathrm{~m}$.

It is now interesting to analyse the evolution of differential settlement over time (Fig. 8). Early in the rainfall $(<4$ days), some soil elements undergo elastic swelling (path $\mathrm{AB}$ or $\mathrm{CD}$ in the case of small/moderate $F$, and path $\mathrm{CD}$ in the case of large $F$ ), while their symmetric counterparts have already yielded (path $\mathrm{DE}$ in the case of small/moderate $F$, and paths $\mathrm{DE}$ or $\mathrm{GH}$ in the case of large $F$ ). This results in increasing values of $\mu\left(\left|\delta_{\mathrm{s}}\right|\right)$ and $\sigma\left(\left|\delta_{\mathrm{s}}\right|\right)$ over time, irrespective of the magnitude of $F$ (Fig. 8). The change in this increasing trend at day 4 for $F \geqslant 1 \mathrm{MN} / \mathrm{m}$ suggests that the soil 


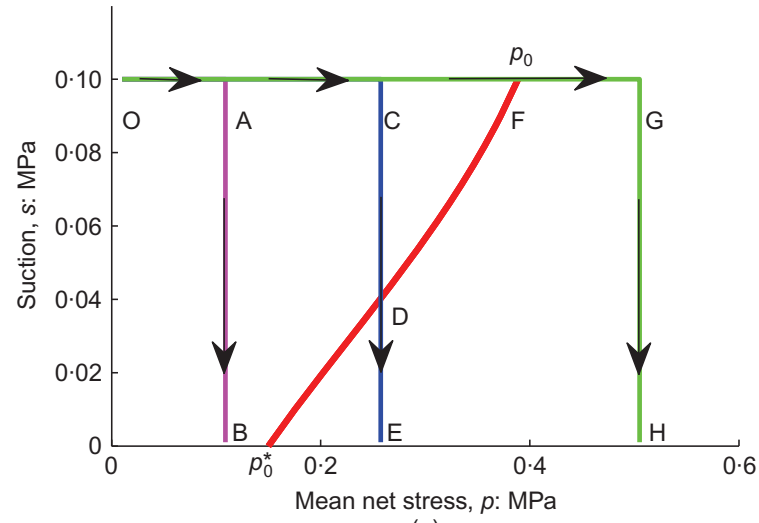

(a)

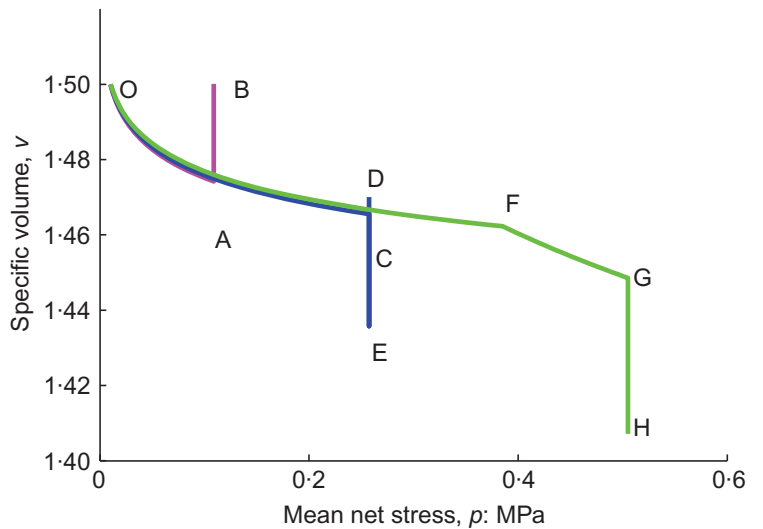

(b)

Fig. 7. Schematic representation of: (a) loading-wetting stress paths relative to initial LC curve; (b) corresponding changes in specific volume

elements, which were following the elastic swelling path CD up to this time, cross the LC yield curve and start collapsing, following path $\mathrm{DE}$. This reduces the difference in $v$ between these elements and their symmetric counterparts, which might have already experienced most of their potential collapse. Conversely, for $F<1 \mathrm{MN} / \mathrm{m}$, the value of $\mu\left(\left|\delta_{\mathrm{s}}\right|\right)$ consistently increases over time, which suggests that symmetric points are most likely to experience wetting paths $\mathrm{AB}$ and $\mathrm{CDE}$ respectively. Note that no result is available from day 8 onwards for $F=8 \mathrm{MN} / \mathrm{m}$, because under this load, and at this time, numerous soil elements reach critical state, causing early termination of the FE analysis. Both $\mu\left(\left|\delta_{\mathrm{s}}\right|\right)$ and $\sigma\left(\left|\delta_{\mathrm{s}}\right|\right)$ stabilise from around day 9 onwards as the water table rises to the ground surface and the soil reaches saturation.

In this paper, the probability of $\left|\delta_{\mathrm{s}}\right|$ exceeding $50 \mathrm{~mm}$ $\left(P_{50}\right)$ is discussed to demonstrate the potential application of the present study to risk and reliability analysis. The limit state of $50 \mathrm{~mm}$ is chosen as it lies within the range of serviceability limits suggested in design codes (e.g. CGS, 2006). However, the trend of the exceedance probability $P_{50}$ does not change significantly across a range of limit states from $25 \mathrm{~mm}$ to $100 \mathrm{~mm}$ (see Le, 2012). Fig. 9 shows the variation of $P_{50}$ against $F$ every 2 days up to day 10 . After day 10 the curve stays virtually unchanged, because in the majority of realisations the value of $\delta_{\mathrm{s}}$ becomes constant, owing to the attainment of full saturation over the entire soil domain.

At any time during the rainfall, the value of $P_{50}$ increases with increasing applied load, and is maximum at day 10 (i.e. at full saturation state) for $F<1 \mathrm{MN} / \mathrm{m}$, but at day 4 (i.e. during transient state) for $F \geqslant 1 \mathrm{MN} / \mathrm{m}$ (Fig. 9). These results emphasise the importance of coupling hydraulic and

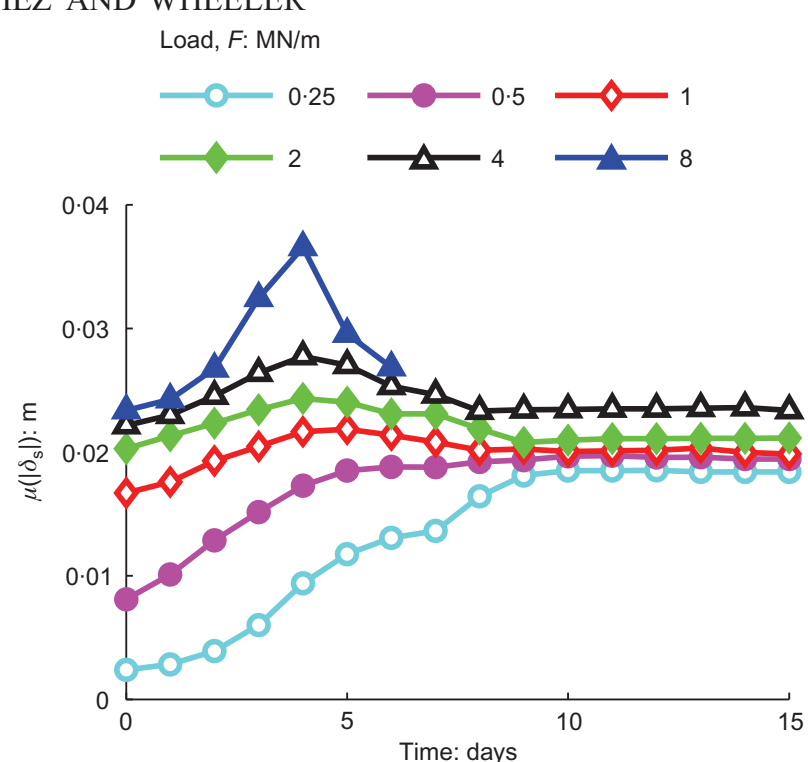

(a)

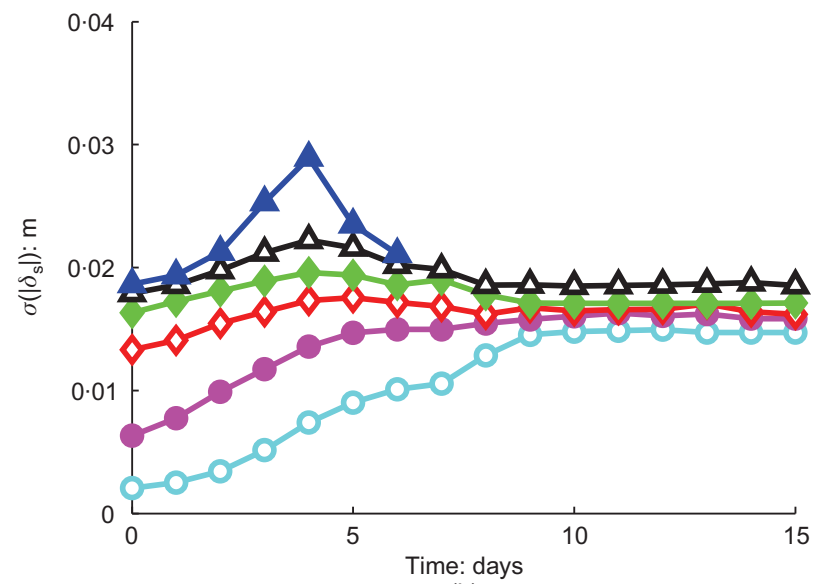

(b)

Fig. 8. Variation of (a) mean $\mu\left(\left|\delta_{s}\right|\right)$ and (b) standard deviation $\sigma\left(\left|\delta_{s}\right|\right)$ of absolute differential settlement over rainfall time for different foundation loads $\left(\mu\left(\Delta p_{0}^{*}\right)=0.02 \mathrm{MPa}, \mathrm{COV}_{\Delta p_{0}^{*}}=0 \cdot 4\right.$, $\left.\theta\left(\Delta p_{0}^{*}\right)=8 \mathrm{~m}\right)$

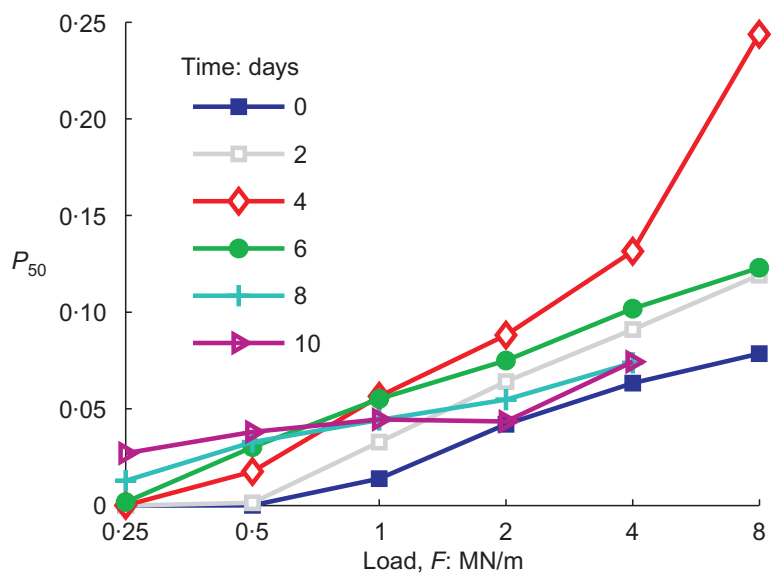

Fig. 9. Variation of exceedance probability $\boldsymbol{P}_{50}$ with foundation load $F$ at different times $\left(\mu\left(\Delta p_{0}^{*}\right)=0.02 \mathrm{MPa}, \mathrm{COV}_{\Delta p_{0}^{*}}=0 \cdot 4\right.$, $\left.\theta\left(\Delta p_{0}^{*}\right)=8 \mathrm{~m}\right)$

mechanical responses, and of conducting a transient analysis to fully capture the risks associated with foundation settlements. Reliability analysis of shallow foundations on heterogeneous unsaturated soils should therefore take into 
consideration not only the applied loads but also the rainfall duration, as significantly different conclusions can be drawn for different combinations of loading and rainfall duration.

\section{Influence of variability characteristics}

The values of $\mu\left(\Delta p_{0}^{*}\right)$ and $\operatorname{COV}_{\Delta p_{0}^{*}}$ determine the magnitude and the degree of variability of the random field of $\Delta p_{0}^{*}$. In order to explore this effect, Fig. 10 presents three schematic scenarios corresponding to soil elements having different initial values of $p_{0}^{*}$ but subjected to the same loading-wetting path. In scenario (1), an initially slightly overconsolidated soil element yields during the application of load $F\left(p_{0}^{*}<p_{0}<p\right)$, and hence undergoes plastic collapse-compression throughout wetting (path $\mathrm{B}_{1} \mathrm{C}_{1} \mathrm{D}_{1}$ in Fig. 10(b)). In scenario (2), an initially overconsolidated soil element does not yield during the application of load $\left(p_{0}^{*}<p<p_{0}\right)$. Therefore, during subsequent wetting, it swells elastically from $\mathrm{B}_{2}$ to $\mathrm{C}_{2}$, but then compresses plastically from $\mathrm{C}_{2}$ to $\mathrm{D}_{2}$. Scenario (3) shows an initially highly overconsolidated soil element that does not yield during the application of load $\left(p<p_{0}<p_{0}^{*}\right)$, and swells elastically throughout wetting (path $\mathrm{B}_{3} \mathrm{C}_{3} \mathrm{D}_{3}$ ).

The variation of $\mu\left(\left|\delta_{\mathrm{s}}\right|\right)$ and $\sigma\left(\left|\delta_{\mathrm{s}}\right|\right)$ over time for the considered ranges of statistical parameters $\mu\left(\Delta p_{0}^{*}\right)(0 \cdot 01-$ $0 \cdot 16 \mathrm{MPa}), \mathrm{COV}_{\Delta p_{0}^{*}}(0 \cdot 2-1 \cdot 6)$ and $\theta\left(\Delta p_{0}^{*}\right)(2-32 \mathrm{~m})$ (with $F$ kept constant at $1 \mathrm{MN} / \mathrm{m})$ is relatively similar to that corresponding to $F=1 \mathrm{MN} / \mathrm{m}$ in Fig. 8: hence only the variation of $P_{50}$ over time is presented in this section. For low values of $\mu\left(\Delta p_{0}^{*}\right)$ scenarios (1) and (2) dominate, and most soil elements experience a decrease in $v$ during the entire rainfall, or at least a significant part of it $\left(B_{1} C_{1} D_{1}\right.$ or

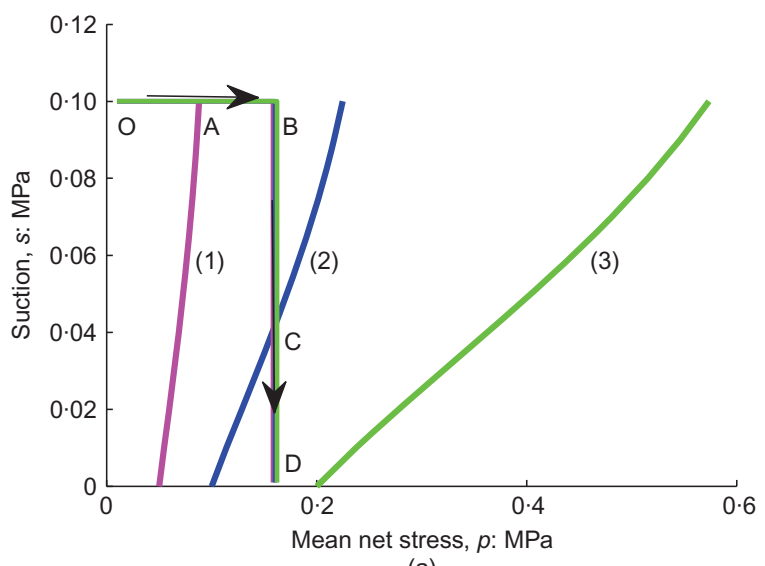

(a)

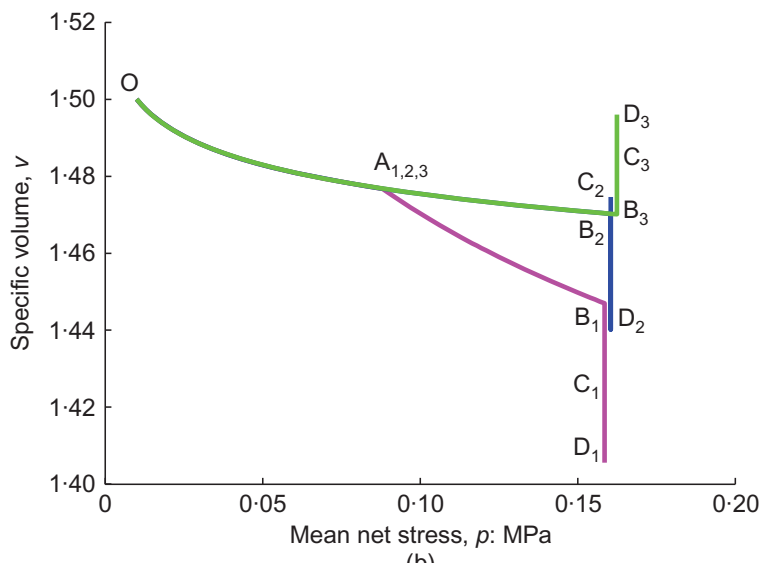

(b)

Fig. 10. Schematic representation of: (a) LC curves corresponding to different degrees of overconsolidation relative to given stress path; (b) corresponding changes in specific volume
$\mathrm{C}_{2} \mathrm{D}_{2}$ in Fig. 10(b)). Therefore the difference of $v$ between symmetrical soil regions does not increase significantly during wetting, resulting in small values of $P_{50}$ (Fig. 11(a)). As the value of $\mu\left(\Delta p_{0}^{*}\right)$ increases up to $0.08 \mathrm{MPa}$, scenarios (2) and (3) become more likely, causing $v$ to evolve in opposite directions over symmetrical soil regions during rainfall (i.e. $\mathrm{B}_{2} \mathrm{C}_{2} \mathrm{D}_{2}$ relative to $\mathrm{B}_{3} \mathrm{C}_{3} \mathrm{D}_{3}$ in Fig. $10(\mathrm{~b})$ ), which leads to the possibility of large $\delta_{\mathrm{s}}$, and hence large $P_{50}$ (Fig. 11(a)). In particular, results suggest that, for a value of $\mu\left(\Delta p_{0}^{*}\right)=0.08 \mathrm{MPa}$, scenarios (2) and (3) occur with relatively similar likelihood on opposite sides of the foundation, and hence result in the largest value of $P_{50}$. However, if $\mu\left(\Delta p_{0}^{*}\right)$ is increased further to $0 \cdot 16 \mathrm{MPa}$, scenario (3) becomes dominant, and the value of $P_{50}$ drops accordingly.

For a given rainfall time, the value of $P_{50}$ attains a maximum at an intermediate value of $\mu\left(\Delta p_{0}^{*}\right)$, which varies depending on the particular time considered (Fig. 11(a)). Prior to the start of the rainfall (day 0 ), the value of $P_{50}$ is highest at a low value of $\mu\left(\Delta p_{0}^{*}\right)=0.02 \mathrm{MPa}$. From day 2 to day 6 , the peak of $P_{50}$ occurs at a low/medium value of
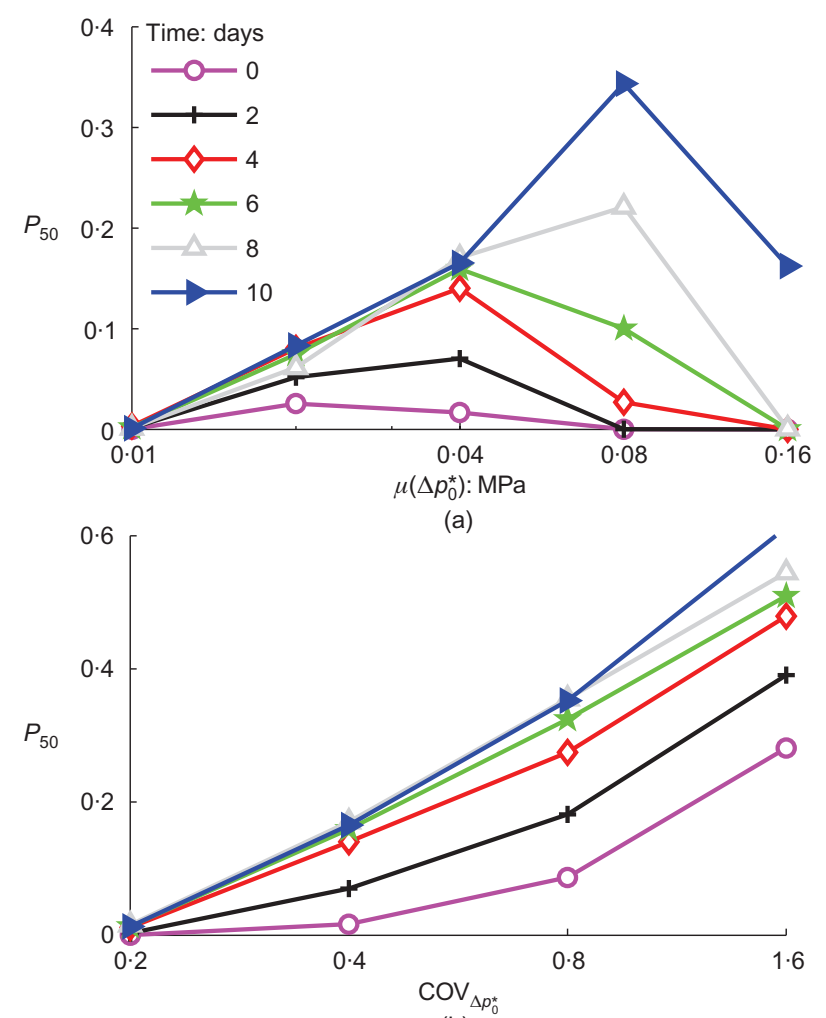

(b)

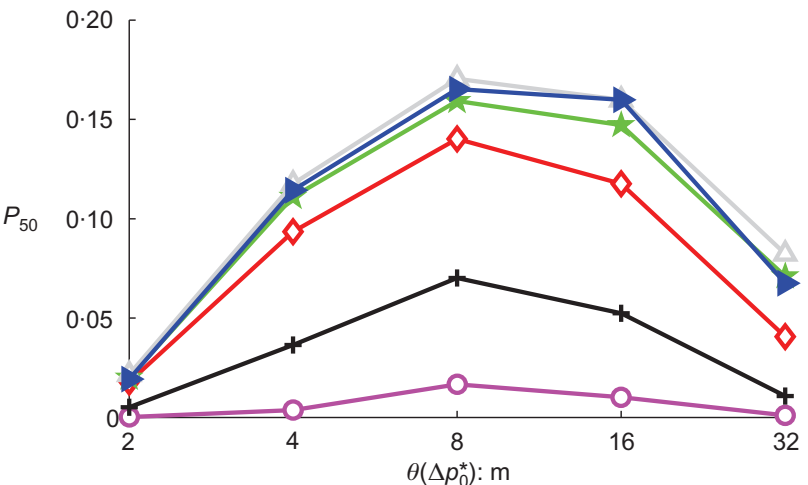

(c)

Fig. 11. Variation of exceedance probability $P_{50}(F=1 \mathrm{MN} / \mathrm{m})$ with: (a) $\mu\left(\Delta p_{0}^{*}\right)\left(\operatorname{COV}_{\Delta p_{0}^{*}}=0 \cdot 4, \theta\left(\Delta p_{0}^{*}\right)=8 \mathrm{~m}\right)$; (b) $\operatorname{COV}_{\Delta p_{0}^{*}}\left(\mu\left(\Delta p_{0}^{*}\right)=\right.$ 0.04 MPa, $\left.\theta\left(\Delta p_{0}^{*}\right)^{*}=8 \mathrm{~m}\right) ; \quad$ (c) $\theta\left(\Delta p_{0}^{*}\right) \quad\left(\mu\left(\Delta p_{0}^{*}\right)^{*}=0 \cdot 04 \mathrm{MPa}\right.$, $\left.\mathrm{COV}_{\Delta p_{0}^{*}}=0 \cdot 4\right)$ 
$\mu\left(\Delta p_{0}^{*}\right)=0.04 \mathrm{MPa}$, whereas, at times later than 6 days, it occurs at a medium/high value of $\mu\left(\Delta p_{0}^{*}\right)=0.08 \mathrm{MPa}$. This pattern suggests that rainfall duration is a very important factor in identifying the critical value of $\mu\left(\Delta p_{0}^{*}\right)$ associated with the highest risk of excessive differential settlements.

The value of $P_{50}$ increases significantly with increasing values of $\operatorname{COV}_{\Delta p_{0}^{*}}$ at any time during the rainfall (Fig. 11(b)). This is because larger values of $\mathrm{COV}_{\Delta p_{0}^{*}}$ cause larger variations of $p_{0}^{*}$, and hence the occurrence of all three scenarios (1), (2) and (3) on symmetrical soil regions becomes similarly probable. There is therefore a higher chance of $v$ changing in opposite directions over symmetrical soil regions during wetting $\left(\mathrm{B}_{1} \mathrm{C}_{1} \mathrm{D}_{1}\right.$ relative to $\mathrm{B}_{3} \mathrm{C}_{3} \mathrm{D}_{3}$ or $\mathrm{B}_{2} \mathrm{C}_{2} \mathrm{D}_{2}$ relative to $\mathrm{B}_{3} \mathrm{C}_{3} \mathrm{D}_{3}$ in Fig. $10(\mathrm{~b})$ ), and hence a higher chance of large $\delta_{\mathrm{s}}$. Conversely, a small value of $\mathrm{COV}_{\Delta p_{0}^{*}}$ leads to small variations of $p_{0}^{*}$ over the soil domain, with a high likelihood of scenarios (1) and (2) (Fig. $10)$. In this case, the difference of $v$ between symmetrical soil regions increases over the initial rainfall period, but tends to stabilise in the later part as the change of $v$ becomes of the same direction on both sides of the foundation $\left(\mathrm{B}_{1} \mathrm{C}_{1} \mathrm{D}_{1}\right.$ relative to $\mathrm{B}_{2} \mathrm{C}_{2} \mathrm{D}_{2}$ in Fig. $\left.11(\mathrm{~b})\right)$. The value of $\delta_{\mathrm{s}}$ therefore tends to be smaller, and hence the values of $P_{50}$ are also smaller.

Figure 11(c) shows that, at any time during the rainfall, the value of $P_{50}$ is maximum at $\theta\left(\Delta p_{0}^{*}\right)=8 \mathrm{~m}$, which is equal to the width of the foundation $(B=8 \mathrm{~m})$. This is consistent with the tendency observed in previous stochastic studies of foundations on randomly heterogeneous saturated soils (e.g. Fenton \& Griffiths, 2002, 2003; Breysse et al., 2005). The fact that the $P_{50}$ attains its maximum value at an intermediate rather than an extreme value of $\theta\left(\Delta p_{0}^{*}\right)$ is also intuitive, as $\delta_{\mathrm{s}}$ should approach zero when $\theta\left(\Delta p_{0}^{*}\right)$ approaches either zero or infinity. The former is because of the 'averaging' effect of soil properties (when $\theta\left(\Delta p_{0}^{*}\right) \ll B$ ). The latter is attributable to the increasing homogeneity of the soil domain (when $\theta\left(\Delta p_{0}^{*}\right) \gg B$ ).

\section{HETEROGENEITY OF POROSITY}

The influence of the heterogeneity of porosity is investigated in this section for different coefficients of variation $\mathrm{COV}_{e}$ and correlation lengths $\theta(e)$. Fig. 12 shows the variation of $\mu\left(\left|\delta_{\mathrm{s}}\right|\right)$ and $\sigma\left(\left|\delta_{\mathrm{s}}\right|\right)$ over time for $\mathrm{COV}_{e}$ ranging from $0 \cdot 2$ to $0 \cdot 8(\theta(e)=8 \mathrm{~m})$. Similar variation patterns are observed for curves obtained for the case with different values of $\theta(e)$. The values of $\mu\left(\left|\delta_{\mathrm{s}}\right|\right)$ and $\sigma\left(\left|\delta_{\mathrm{s}}\right|\right)$ attain a maximum at intermediate times $(\sim 4$ days $)$ during the rainfall. At this time, the wetting front on one side of the foundation reaches the saturated region below the water table (e.g. Figs 5(e), 5(f)). This transient state corresponds to the maximum variation of suction across the foundation base, producing the largest values of $\mu\left(\left|\delta_{\mathrm{s}}\right|\right)$ and $\sigma\left(\left|\delta_{\mathrm{s}}\right|\right)$. The values of $\mu\left(\left|\delta_{\mathrm{s}}\right|\right)$ and $\sigma\left(\left|\delta_{\mathrm{s}}\right|\right)$ then start to decrease gradually, and become constant from day 12 onwards, corresponding to the attainment of the fully saturated state with the water table at ground surface (e.g. Figs 5(i), 5(j)).

The FE simulations with random soil porosity take a very long time, and are prone to numerical instability owing to extreme values of permeability. Therefore only $\sim 150-200$ realisations were performed for each combination of statistical parameters.

During rainfall infiltration, water migrates preferentially either through saturated regions of large porosity or through unsaturated regions of a high degree of saturation (Le, 2012; Le et al., 2012). This is because large porosity induces high saturated permeability (equation (3)), whereas high saturation causes high relative permeability (equation (4)) and reduces the amount of water required to saturate the soil.

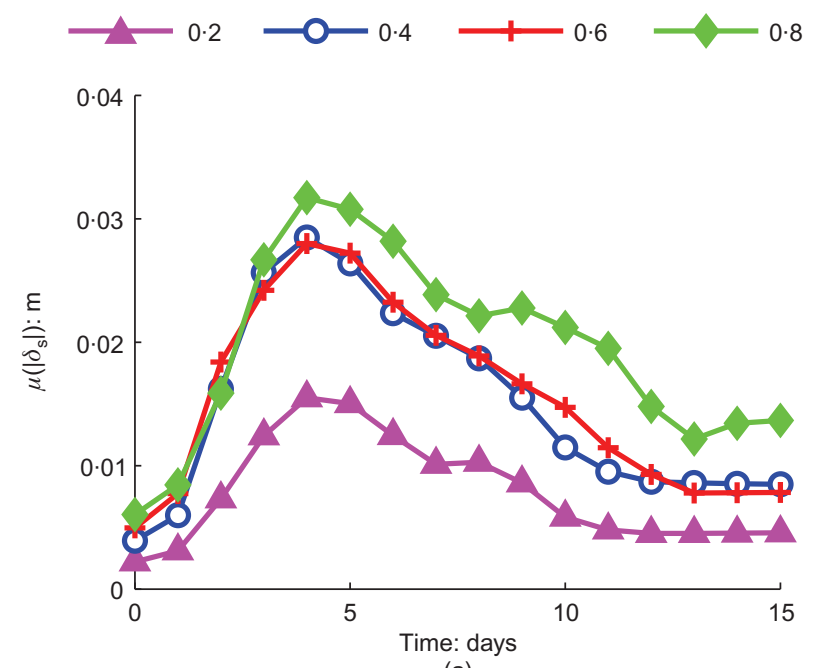

(a)

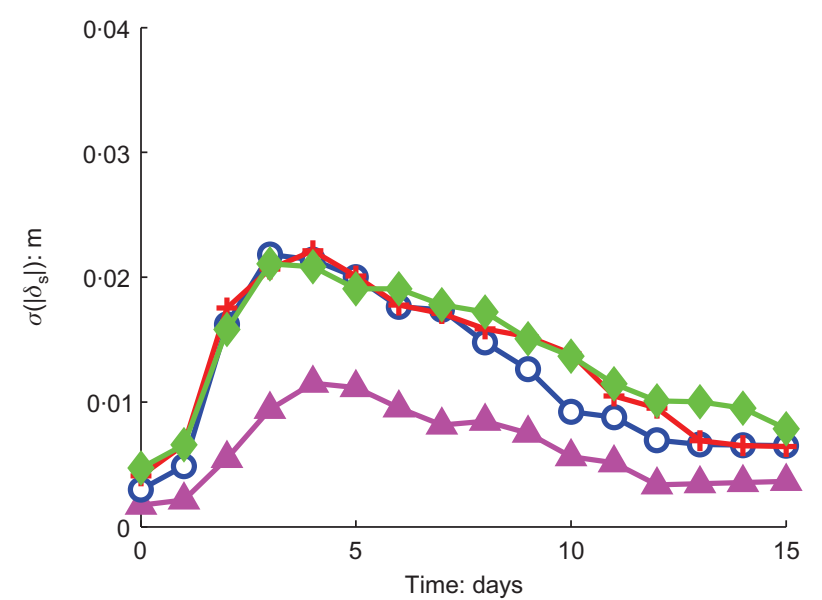

(b)

Fig. 12. Variation of (a) mean $\mu\left(\left|\delta_{s}\right|\right)$ and (b) standard deviation $\sigma\left(\left|\delta_{\mathrm{s}}\right|\right)$ of absolute differential settlement over rainfall time and for different values of $\mathrm{COV}_{e}(\mu(e)=0 \cdot 5, \theta(e)=8 \mathrm{~m})$

Suction drops faster along preferential water migration paths, leading to earlier onset of collapse or failure, and hence earlier onset of settlements. Time difference in the settlement onset and variation in the settlement amount of different soil regions cause differential settlements. As porosity differences between soil regions increase (i.e. larger values of $\mathrm{COV}_{e}$ ), the variability in suction across the soil domain becomes greater, and the exceedance probability $P_{50}$ increases accordingly (Fig. 13(a)). The value of $P_{50}$ attains a maximum at $\theta(e)=B=8 \mathrm{~m}$, in agreement with the trend observed for random $p_{0}^{*}$ (Fig. 13(b)). This suggests that a correlation length equal to the foundation width poses the highest risk of large differential settlements for a range of soil properties.

\section{CONCLUSIONS}

This study employs Monte Carlo simulations to investigate stochastically the occurrence of rainfall-induced differential settlements between the ends of a rigid shallow foundation on randomly heterogeneous soil. The foundation is situated on an unsaturated soil domain with spatially varying preconsolidation stress or porosity. The BBM is used to describe the mechanical behaviour of the unsaturated soil, and the van Genuchten relationships are employed to model unsaturated flow. The FE method is combined with random fields to represent soil heterogeneity. 


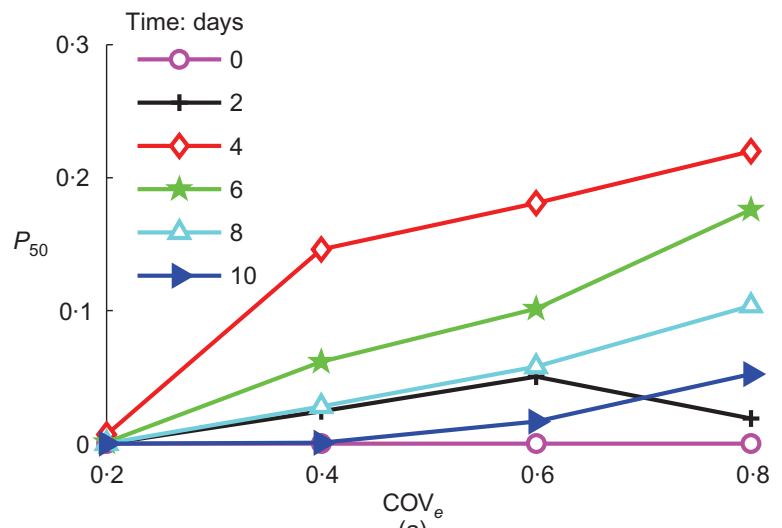

(a)

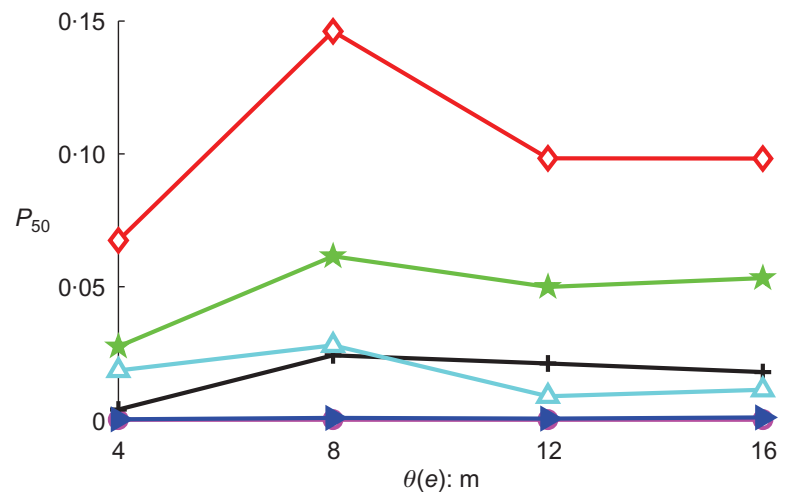

(b)

Fig. 13. Variation of exceedance probability $\boldsymbol{P}_{\mathbf{5 0}}$ at different times during rainfall with: (a) coefficient of variation $\operatorname{COV}_{e}(\mu(e)=0 \cdot 5$, $\theta(e)=8 \mathrm{~m})$; (b) correlation length $\theta(e)\left(\mu(e)=0 \cdot 5, \mathrm{COV}_{\mathrm{e}}=0 \cdot 4\right)$

The analyses show that the amount of differential settlement varies depending on foundation load, variability statistics and rainfall duration. The normal distribution captures remarkably well the probability distribution of differential settlements. Assuming a normal distribution, the exceedance probability of differential settlements to be greater than a serviceability limit (in this study equal to $50 \mathrm{~mm}$ ) can be estimated

For the case of random preconsolidation stress, an increase of foundation load causes an increase in both the mean and the standard deviation of differential settlements. The exceedance probability is highest during the transient stage of infiltration for large applied loads $(\geqslant 1 \mathrm{MN} / \mathrm{m})$, but becomes largest when the soil is close to saturation for small applied loads $(<1 \mathrm{MN} / \mathrm{m})$.

Investigation of statistical parameters shows that the value of the exceedance probability

(a) is largest early in the rainfall for low/medium values of the mean of the random increment of preconsolidation stress, and at later times for medium/high values of the same increment

(b) increases with increasing soil variability (i.e. larger coefficient of variation) for both cases of random preconsolidation stress and random porosity

(c) reaches a maximum at a correlation length equal to the foundation width for both cases of random preconsolidation stress and random porosity.

The study also demonstrates that the variation of the mean and standard deviation of differential settlement and of exceedance probability (with time, foundation load and statistical parameters) can be explained in a consistent way by the concepts of the BBM. In particular, the study shows that the changes of specific volume caused by wetting- induced swelling or collapse play a significant role in the evolution of differential settlements during rainfall.

The work also highlights that structures supported by rigid foundations on unsaturated soils with heterogeneous distributions of preconsolidation stress or porosity can experience tilting and/or cracking as a consequence of rainfall infiltration. A coupled hydraulic-mechanical analysis and a realistic representation of unsaturated soil behaviour are necessary to quantify this risk. Moreover, when evaluating the probability of exceeding a certain serviceability limit, it is important to analyse the entire rainfall duration, as differential settlements evolve in a non-monotonic way during the transient phase of infiltration.

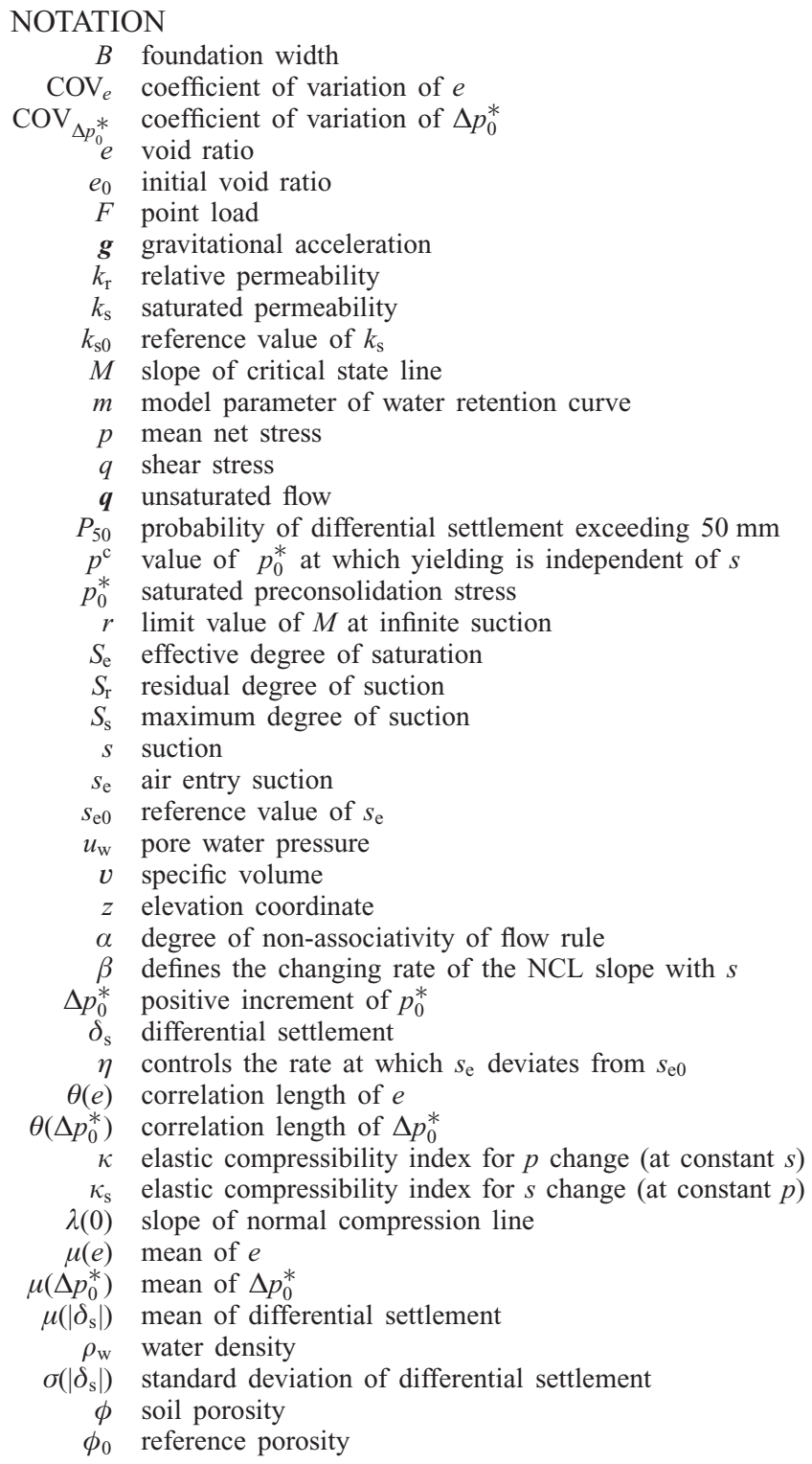

\section{REFERENCES}

Alonso, E., Gens, A. \& Josa, A. (1990). A constitutive model for partially saturated soils. Géotechnique 40, No. 3, 405-430, http://dx.doi.org/10.1680/geot.1990.40.3.405.

Baecher, G. B. \& Ingra, T. S. (1981). Stochastic FEM in settlement predictions. J. Geotech. Engng Div., ASCE 107, No. 4, 449463.

Bartlett, S. F. \& Alcorn, P. (2004). Estimation of preconsolidation stress and compression ratio from field and laboratory measurements from the I-15 reconstruction project, Salt Lake City, Utah. 
Salt Lake City, UT, USA: Department of Civil and Environmental Engineering, University of Utah.

Bolzon, G., Screfler, B. A. \& Zienkiewicz, O. C. (1996). Elastoplastic soil constitutive laws generalised to partially saturated states. Géotechnique 46, No. 2, 279-289, http://dx.doi.org/ 10.1680/geot.1996.46.2.279.

Breysse, D., Niandou, H., Elachachi, S. \& Houy, L. (2005). A generic approach to soil-structure interaction considering the effects of soil heterogeneity. Géotechnique 55, No. 2, 143-150, http://dx.doi.org/10.1680/geot.2005.55.2.143.

CGS (2006). Canadian foundation engineering manual. Montreal, Quebec, Canada: Canadian Geotechnical Society.

Fenton, G. A. (1990). Simulation and analysis of random field. $\mathrm{PhD}$ thesis, Civil Engineering and Operations Research, Princeton University, Princeton, NJ, USA.

Fenton, G. A. \& Griffiths, D. V. (2002). Probabilistic foundation settlement on spatially random soil. J. Geotech. Geoenviron. Engng 128, No. 5, 381-390.

Fenton, G. A. \& Griffiths, D. V. (2003). Bearing capacity of spatially random $c-$ phi soils. Can. Geotech. J. 40, No. 1, 54-65.

Fenton, G. A., Griffiths, D. V. \& Cavers, W. (2005). Resistance factors for settlement design. Can. Geotech. J. 42, No. 5, 1422-1436.

Fredlund, D. G., Morgenstern, N. R. \& Widger, R. A. (1978). The shear strength of unsaturated soils. Can. Geotech. J. 15, No. 3, $313-321$.

Gallipoli, D., Gens, A., Sharma, R. \& Vaunat, J. (2003). An elastoplastic model for unsaturated soil including the effect of saturation degree on mechanical behaviour. Géotechnique 53, No. 1, 123-135, http://dx.doi.org/10.1680/geot.2003.53.1.123.

Griffiths, D. V. \& Fenton, G. A. (2009). Probabilistic settlement analysis by stochastic and random finite-element methods. J. Geotech. Geoenviron. Engng 135, No. 11, 1629-1637.

Josa, A., Balmaceda, A., Gens, A. \& Alonso, E. E. (1992). An elastoplastic model for partially saturated soils exhibiting a maximum of collapse. Proceedings of the 3 rd international conference on computational plasticity, Barcelona, Spain, pp. 815-826.

Karube, D. (1988). New concept of effective stress in unsaturated soil and its proving test. In Advanced triaxial testing of soil and rock (eds R. T. Donaghe, R. C. Chaney and M. L. Silver), ASTM STP 977, pp. 539-552. West Conshohocken, PA, USA: ASTM International.

Karube, D. \& Kawai, K. (2001). The role of pore water in the mechanical behaviour of unsaturated soils. Geotech. Geol. Engng 19, No. 3-4, 211-241.

Kawai, K., Iizuka, A., Hayakawa, E. \& Wang, W. (2007). Nonuniform settlement of compacted earth structures caused by the deformation characteristics of unsaturated soil on wetting. Soils Found. 47, No. 2, 195-205.

Kozeny, J. (1927). Über kapillare Leitung des Wassers im Boden. Sitzungsber. Akad. Wiss., Wien 136, No. 2a, 271-306 (in German).
Le, T. M. H. (2012). Stochastic modelling of slopes and foundations on heterogeneous unsaturated soils. $\mathrm{PhD}$ thesis, School of Engineering, University of Glasgow, UK.

Le, T. M. H., Gallipoli, D., Sanchez, M. \& Wheeler, SJ. (2012). Stochastic analysis of unsaturated seepage through randomly heterogeneous earth embankments. Int. J. Numer. Analyt. Methods Geomech. 36, No. 8, 1056-1076.

Met Office (2011). Fact sheet No. 3: Water in the atmosphere. Exeter, UK: The Met Office.

Olivella, S., Gens, A., Carrera, J. \& Alonso, E. (1996). Numerical formulation for a simulator (CODE-BRIGHT) for the coupled analysis of saline media. Engng Comput. 13, No. 7, 87-112.

Paice, G. M, Griffiths, D. V \& Fenton, G. A. (1994). Influence of spatially random soil stiffness on foundation settlement. Proceedings of the conference on vertical and horizontal deformations of foundations and embankments, College Station, TX, USA, pp. 628-639.

Paice, G. M., Griffiths, G. V. \& Fenton, G. A. (1996). Finite element modeling of settlement on spatially random soil. ASCE J. Geotech. Engng 122, No. 9, 777-779.

Popescu, R., Deodatis, G. \& Nobahar, A. (2005). Effects of random heterogeneity of soil properties on bearing capacity. Prob. Engng Mech. 20, No. 4, 324-341.

Resendiz, D. \& Herrera, I. (1969). A probabilistic formulation of settlement control design. Proceedings of the 7th international conference on soil mechanics and foundation engineering, Mexico City, Mexico, Vol. 2, pp. 217-225.

Rodriguez, R. (2006). Hydrogeotechnical characterization of a metallurgical waste. Can. Geotech. J. 43, No. 10, 1042-1060.

UPC (2009). CODE_BRIGHT user's guide: A 3-D program for thermo-hydro-mechanical analysis in geological media. Barcelona, Spain: Department of Geotechnical Engineering and Geosciences, Universitat Politècnica de Catalunya.

van Genuchten, M. T. (1980). A closed-form equation for predicting the hydraulic conductivity of unsaturated soils. Soil Sci. Soc. Am. J. 44, No. 5, 892-898.

van Genuchten, M. T. \& Nielsen, D. R. (1985). On describing and predicting the hydraulic properties of unsaturated soils. Ann. Geophys. 3, No. 5, 615-627.

Wheeler, S. J., Sharma, R. S. \& Buisson, M. S. R. (2003). Coupling of hydraulic hysteresis and stress-strain behaviour in unsaturated soils. Géotechnique 53, No. 1, 41-54, http://dx.doi.org/ 10.1680/geot.2003.53.1.41.

Wu, T. H. \& Kraft, L. M. (1967). The probability of foundation safety. J. Soil Mech. Found. Div., ASCE 93, No. SM5, 213-231.

Zandarín, M. T., Oldecop, L. A., Rodríguez, R. \& Zabala, F. (2009). The role of capillary water in the stability of tailing dams. Engng Geol. 105, No. 1-2, 108-118.

Zeitoun, D. G. \& Baker, R. (1992). A stochastic approach for settlement predictions of shallow foundations. Géotechnique $\mathbf{4 2}$, No. 4, 617-629, http://dx.doi.org/10.1680/geot.1992.42.4.617. 